\title{
Syndromic surveillance and UEFA Euro 2016 in France - Health impact assessment
}

\author{
Erica Fougère, Céline Caserio-Schönemann*, Jamel Daoudi, Anne Fouillet, \\ Marc Ruello, Isabelle Pontais, Manuel Zurbaran, Emmanuel Lahaie and Anne Gallay
}

\author{
Santé publique France, SAINT-MAURICE, France
}

\section{Objective}

To describe the surveillance indicators implemented for the health impact assessment of a potential health event occurring before, during or after the UEFA Euro 2016 football matches in order to timely implement control and prevention measures.

\section{Introduction}

France hosted 2016 UEFA European Football Championship between June 10 and July 10. In the particular context of several terrorist attacks occurring in France in 2015 [1], the French national public health agency «Santé publique France » (formerly French Institute for Public Health Surveillance-InVS) was mandated by the Ministry of Health to reinforce health population surveillance systems during the UEFA 2016 period. Six French regions and 10 main stadiums hosted 51 matches and several official and nonofficial dedicated Fan Zones were implemented in many cities across national territory. Three types of hazard have been identified in this context: outbreak of contagious infectious disease, environmental exposure and terrorist attack.

The objectives of health surveillance of this major sporting event were the same as for an exceptional event including mass gathering [2] : 1/ timely detection of a health event (infectious cluster, environmental pollution, collective foodborne disease...) to investigate and timely implement counter measures (control and prevention), 2/ health impact assessment of an unexpected event. The French national syndromic surveillance system SurSaUD ${ }^{\circledR}$ was one of the main tools for timely health impact assessment in the context of this event.

\section{Methods}

French national syndromic $\operatorname{SurSaUD}{ }^{\circledR}$ system has been set up in 2004 and supervised by Santé publique France for 12 years. It allows the daily automatic collation of individual data from over 650 emergency departments (ED) involved in the OSCOUR ${ }^{\circledR}$ network and 61 emergency general practitioners' (GPs) associations (SOS Médecins) [3]. About 60,000 attendances in ED (88\% of the national attendances) and 8,000 visits in SOS Médecins associations ( $95 \%$ of the national visits) are daily recorded all over the territory and transmitted to Santé publique France.

Medical information such as provisional medical diagnosis coded according to the International Classification of Diseases, 10th Revision (ICD-10) for EDs and specific thesaurus for SOS Médecins is routinely monitored through different syndromic indicators (SI). SI are defined by medically relevant clusters of one or several diagnoses, serving as proxies for conditions of public health interest.

From June 10 to July 10,19 SI were daily analyzed through automatic national and regional dashboards. SI were divided into 3 groups of public health surveillance interest :

$1 /$ description of population health: injuries, faintness, myocardial infarction, alcohol, asthma, heat-related symptoms, anxious troubles ;

2/ infectious diseases/symptoms with epidemic potential or diseases/symptoms linked with an environmental exposure: fever, fever associated with cutaneous rash, meningitis, pneumonia, gastroenteritis, collective foodborne disease ;
3/ symptoms potentially linked with a CBRN-E exposure: influenza-like illness, burns, conjunctivitis, dyspnea/ difficulty breathing, neurological troubles, acute respiratory failure.

Daily analysis were integrated into specific UEFA 2016 surveillance bulletins and daily sent to the Ministry of Health including week-ends.

\section{Results}

SI followed during the UEFA Euro 2016 period were nonspecific and potentially affected or influenced by several events appart from the championship. Between June 10 and July 10, two moderate heat-wave periods occurred on a large part of mainland France : the first one from June 22 to 25 (beginning in the West-South of France and then moving North and East of the country) and the second one from July 8 to 11 in the East-South. An increase in heat-related indicators (hyperthermia/heat stroke, dehydration, hyponatremia and burns) has been observed during both periods in five French regions including four hosting regions. Only minor increases in the other SI followed during the Euro 2016 period were observed.

\section{Conclusions}

Health surveillance implemented during 2016 UEFA European Football Championship through a daily analysis of non-specific SI from the French syndromic surveillance system SurSaUD ${ }^{\circledR}$ did not show any major variation associated with the sporting event. The observed variations were related with specific environmental conditions (heat-waves). Together with the health surveillance system, preventive plans were set up during the event essentially by offering flyers with information and useful tips on the main preventive attitudes and measures to adopt in a summer festive context (risks associated with alcohol and drug intake, injuries, heat and sun exposure, dehydration, unprotected sexual behaviour...).

\section{Keywords}

UEFA 2016; SurSaUD; health impact assessment; France; mass gathering

\section{Acknowledgments}

To OSCOUR $®$ and SOS Médecins partners and to the regional SurSaUD $\mathbb{R}$ team

\section{References}

[1] Vandentorren S, Paty AC, Baffert E, et al. Syndromic surveillance during the Paris terrorist attacks. 387, No. 10021, p846-847, 27 February 2016

[2] Lombardo J, Sniegoski C, Loschen W, et al. Public health surveillance for mass gatherings. Johns Hopkins APL Tech Dig 2008;27(4): 347-355

[3] Caserio-Schönemann C, Bousquet V, Fouillet A, Henry V. The French syndromic surveillance system SurSaUD ${ }^{\circledR}$. Bull Epidémiol Hebd 2014;3-4:38-44

\section{*Céline Caserio-Schönemann}

E-mail: Celine.CASERIO-SCHONEMANN@santepubliquefrance.fr 